\title{
Wii Game for Surgical Training in Residents at The Instituto Mexicano del Seguro Social in Mexico City
}

\section{José Luis Mosso Vázquez ${ }^{1,2 *}$, Juan Raúl Maldonado Coronado², Gregorio Tomás Obrador Vera², Michelle Vanegas Medellin² $^{2}$ Ana Rivera García Granados ${ }^{2}$}

${ }^{1}$ General Hospital 25, Mexican Institute of Social Security IMSS, Mexico

${ }^{2}$ School of Medicine, Panamericana University, Mexico

*Corresponding Author: José Luis Mosso Vázquez, General Hospital 25, Mexican Institute of Social Security IMSS, Mexico.

Received: May 21, 2019; Published: July 04, 2019

DOI: 10.31080/ASGIS.2019.02.0055

\begin{abstract}
Background: To develop surgical skills rapidly in endoscopic surgery is necessary to be trained in different physical and virtual models. Recently a video game has been used with this propose by Bokhari, et al.

Aim of the study: To build an adaptative device integrated with Wii and a laparoscopic grasper and to demonstrate the utility of the system for laparoscopic surgery training in Residents of surgery.

Methods: We designed an acrylic base to support Wii and a laparoscopic grasper. Six residents of surgery participated in this project. The experimental group was integrated by two residents of the first year of the specialization; there were two control groups; one integrated by 2 residents of the first year and another of 2 residents of second year from a National Medical Center. Only the residents of the experimental group trained with Wii during 6 months. After that period, we measured the time to perform 3 different tasks in all residents, involving the use of needle, geometric figures and rice.

Result: The two residents who played Wii game during 6 months were able to make knots, sutures and to move geometric figures in shorter time than the control groups.

Conclusion: Wii game seems to be an excellent tool to train residents to develop visuomotor coordination, facilitating to make surgical endoscopic tasks like manipulation of surgical tools and improved control of laparoscopic grasper. Wii could also be a complementary tool for training undergraduate students at the schools of Medicine.
\end{abstract}

Keywords: Video Games; Medical Education; Surgery; Training

\section{Introduction}

To develop surgical skills rapidly in endoscopic surgery is necessary to be trained in different physical and virtual models, with the proposal to reduce time learning and intraoperative complications on humans. Surgical education in laparoscopy before surgical procedure on humans could be provided in different models such as: cadaver, animals, physical trainers, and virtual trainer devices $[1,2]$. However, researchers in surgical education have been demonstrated the advantages of videogame in training [3-11]. Assessment results of entertainment games have been an interest for sur- gical education by Bokhari, et al. at the Minnesota University. This group attached a particular device to the remote control of a Wii game to hold a part of surgical grasper for endoscopic surgery [12]. With the interaction of Marble Mania game, users were able to interact in a virtual game making the same movements of the surgeon wrist (Up, Down, Right and left, left and right rotation). Generally, the simulators used in training are big, heavy and expensive. This option represents a cheaper, lighter and smaller model that could be an alternative tool in the training of residents, interns and undergraduate students. 


\section{Methodology}

All residents under informed consent who participate in this project were in the residency of surgery from the National Medical Center la Raza in Mexico City (table 1).

The experimental group was integrated by two residents of the first year since the first day of their residency of surgery, in the first year they were in the Hospital General y Regional number 25 of the Instituto Mexicano del Seguro Social in Mexico City with their consent authorization accepted to participate in the project with the mission to develop surgical skill for endoscopic surgery playing Wii game for at least 30 hours in six months and with all degrees of difficulty of the game Marble Mania. They didn't know that in the end of the first six months of the residency we were going to measure their surgical time in some tests involving sutures, knots and moving skills comparing them with the other residents of general hospitals. The first control group was integrated of two residents of first year of residency of surgery from the Hospital General No. 27 of the IMSS. The second control group was integrated of 2 residents of second year of residency in surgery IMSS. Residents from control groups participated with one session in the end of the six months of the residency without knowing they were participating in a project related with an experimental group from Hospital General y Regional No. 25 of the same Institutions (IMSS). Wii game was integrated of an acrylic base to hold the WiiMote ${ }^{\circledR}$ (Nintendo $\mathrm{Wii}^{\circledR}$ remote) attached to a half of grasper (Laparoscopic tool), a big screen of TV, and a Wii game Marble Mania ${ }^{\circledR}$ were used (See figure 2). The acrylic base had a hole with a spherical device to hold a port of $10 \mathrm{~mm}$ diameter and through it we introduced the grasper attached to the WiiMote ${ }^{\circledR}$. The minitrainer used to evaluate residents to transfer geometric items, to cross a needle in a simulator tissue, and to move 7 rices was Re-designed in Mexico for Mosso et al. It consisted of a small base fixed on a table with a micro camera at the top. The micro camera displayed on the screen of a Vuzix Head Mounted Display instead of a big screen on a TV. The surgical tools used were two graspers to transfer geometric items and to move 7 rices, and one needle holder to cross totally a needle into a piece of tissue. We measured the time required to perform the following 3 tasks in all residents: to cross a needle on a tissue (task 1), to move 7 rice into a square (task 2), and moving geometric items from one place to another (task 3), all tasks in a portable trainer.

\begin{tabular}{|c|c|c|c|c|c|c|}
\hline Category & Hospital & Age & Sex & $\begin{array}{c}\text { Played Wii } \\
\text { Before }\end{array}$ & $\begin{array}{c}\text { Previous Surgical training } \\
\text { with Wii game (hrs) }\end{array}$ & $\begin{array}{c}\text { Time in Residence } \\
\text { (months) }\end{array}$ \\
\hline R1 & HGR 25 & 23 & Male & No & 40 & 6 \\
\hline R1 & HGR 25 & 25 & Male & No & 40 & 6 \\
\hline R1 & HGR 27 & 27 & Male & Yes & 0 & 6 \\
\hline R1 & HGR 27 & 25 & Male & Yes & 0 & 6 \\
\hline R2 & CMN Raza & 28 & Male & No & 0 & 18 \\
\hline R2 & CMN Raza & 28 & Female & No & 0 & 18 \\
\hline
\end{tabular}

Table 1: Residents from The Instituto Mexicano del Seguro Social, Mexico City.

\section{Result}

For analysis, we divided residents into 3 groups, according to their characteristics. Group 1: those who have played Wii before and trained with the game; group 2, those who have played Wii before but didn't train with the game and group 3, those who haven't played before, didn't train with the game but are residents of the second year of Surgery. Tasks were ordered by difficulty starting from easiest to hardest. Results in time are shown in Graph 1.
As shown in graph 1, the time taken in performing the first task by the residents in group 1 was less than the time taken by group 2 and considerably less than the time taken by group 3 . Task 2 seems to have the same pattern as task 1 ; task 3 , which requires much more ability to be successfully performed, was best made by group 3 but not by much followed by group 1 . 


\begin{tabular}{|c|c|c|c|c|c|c|c|c|c|}
\hline Groups & $\begin{array}{l}\text { Grade in } \\
\text { Residency } \\
\text { of surgery }\end{array}$ & Hospital & Age & Gender & $\begin{array}{c}\text { Have } \\
\text { played Wii } \\
\text { before? }\end{array}$ & $\begin{array}{c}\text { Trained } \\
\text { with } \\
\text { Wii? }\end{array}$ & $\begin{array}{c}\text { Task 01: Time To } \\
\text { cross a needle } \\
\text { through a tissue } \\
\text { (secs) }\end{array}$ & $\begin{array}{c}\text { Task 02: } \\
\text { Time To } \\
\text { move } 7 \text { rices } \\
\text { (secs) }\end{array}$ & $\begin{array}{l}\text { Task 03: Time } \\
\text { To transfer } \\
5 \text { geometric } \\
\text { items (secs) }\end{array}$ \\
\hline 1 & RI & HGR 25 & 23 & Male & yes & yes & 84 & 105 & 278 \\
\hline 1 & RI & HGR 25 & 25 & Male & yes & yes & 67 & 72 & 240 \\
\hline 2 & RI & HGZ 27 & 27 & Male & yes & no & 95 & 185 & 240 \\
\hline 2 & R I & HGZ 27 & 25 & Male & yes & no & 88 & 85 & 366 \\
\hline 3 & R II & CMN Raza & 28 & Male & no & no & 410 & 127 & 285 \\
\hline 3 & R II & CMN Raza & 28 & Female & no & no & 417 & 280 & 188 \\
\hline
\end{tabular}

Table 2: Time taken in performing the 3 tasks in seconds.

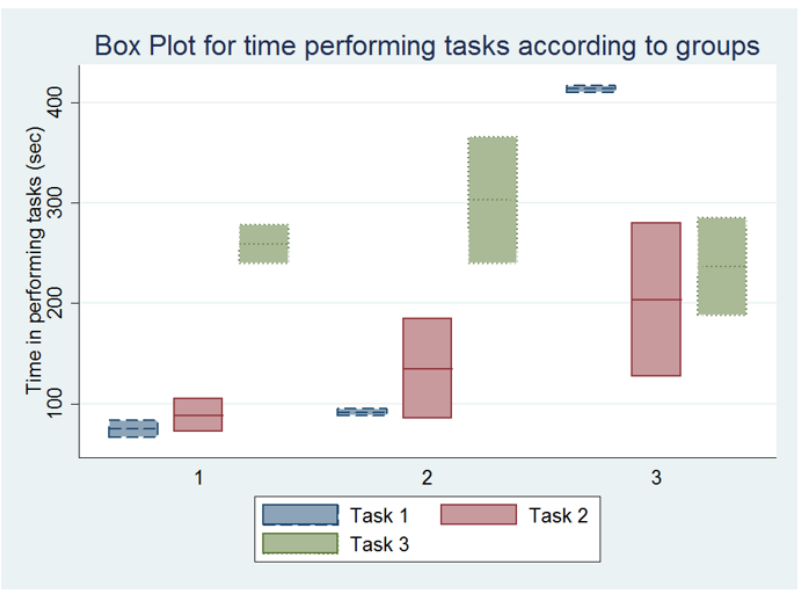

Figure 1: Results. Box Plot for time performing tasks according to groups. (Group 1: Have played Wii before and have trained with Wii; Group 2: Have played Wii before and haven't trained with Wii; Group 3: Haven't played Wii before and haven't trained with Wii but are residents of second year).

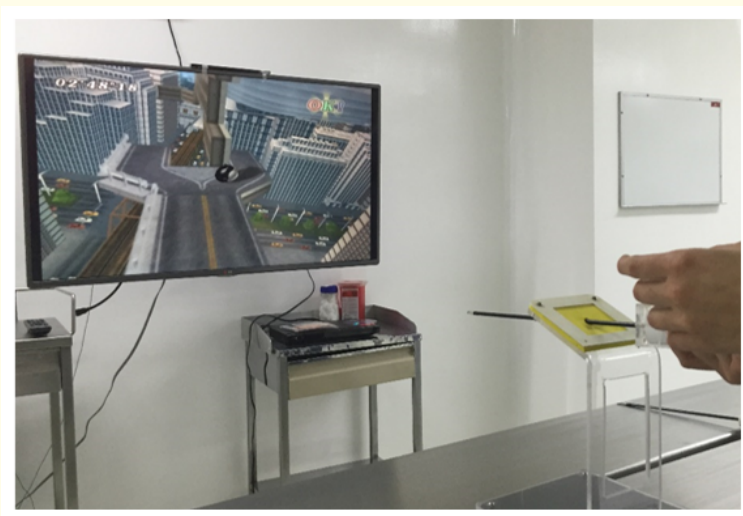

Figure 2: Wii game and scenario of Marble game. School of Medicine, Universidad Panamaricana. Mexico City.

\section{Discussion and Conclusion}

By the above results, Nintendo $\mathrm{Wii}^{\circledR}$ game helped residents to develop skills for endoscopic navigation such as manipulation of surgical tools and positioning (Using the wrist motions only). The surgical tasks, where residents need fingers, are not the best option to be developed by this device. However future games where user's fingers will be involved could be an excellent option to perform surgical tasks with high level of difficulty such as performing sutures or knots. The current and future generations of residents and undergraduate students of medicine have more relationship with new games where navigation is the main objective and undoubtedly future games will have more immersion and feedback devices. When asked to 42 undergraduate students of second year at the school of medicine at the Universidad Panamericana, 40 students would accept the Nintendo $\mathrm{Wii}^{\circledR}$ device game in the Medicine program because all of them know the game, most of them have played it and all of them know endoscopic surgery. As demonstrated before by Bokhari et al. Wii seems to be an cheaper, lighter and smaller training model that could be an alternative tool in the training of residents, interns and undergraduate students. It is important also recognize our new contribution to improve the Bokhari device, which is a spherical device integrated to hold a real laparoscopic port to introduce the Wii-mote, because we considered this spherical device give Wii-mote more degrees of freedom. Preliminary results indicate us that with a higher number of participants the results might be statistically significant and prove the usefulness of the device with Wii game presented in this project.

\section{Acknowledgment}

I thank José Luis Mosso Lara, my son, who gave me all his games including Wii, to make possible this research. 


\section{Bibliography}

1. AG Gallagher., et al. "Virtual reality training in laparoscopic surgery: a preliminary assessment of Minimally Invasive Surgical Trainer Virtual Reality (MIST VR)". Endoscopy 31 (1999): 310-313.

2. R Aggarwal., et al. "Laparoscopic skills training and assessment". British Journal of Surgery 91 (2004): 1549-1558.

3. K Kahol., et al. "Measuring movement expertise in surgical tasks". presented at 14th Annual ACM International conference on Multimedia Santa Barbara, CA, (2006).

4. K Kahol., et al. "The effect of real-time visualization of skill on surgical training". presented at Medicine Meets Virtual Reality, Long Beach, CA, (2007).

5. K Kahol., et al. "The Effect of fatigue on psychomotor and cognitive skills". American Journal of Surgery 195 (2008): 195204.

6. M J Curet. "The Impact of Video Games on Training Surgeons in the 21st Century-Invited Critique". Archives of Surgery 142 (2007): 186.

7. Bradley H., et al. "Can Video Games be Used to Predict or Improve Laparoscopic Skills?". Journal of Endourology 19.3 (2005): 372-376.

8. K Kahol., et al. "The effect of short term pre-trial practice on surgical proficiency in simulated environments: A Randomized Trial of the "Pre-operative Warm-up" Effect". Journal of American College of Surgeons 208 (2009): 255-268.

9. K Kahol., et al. "TR 1001344: The effectiveness of unstructured learning of skills in surgery". Arizona State University, Phoenix, AZ (2010).

10. Henk WR., et al. "Implementation of simulation in surgical practice: Minimally invasive surgery has taken the lead: The Dutch experience". Medical Teacher 33 (2011): 105-115.
11. Joe Uccelli., et al. "The validity of take-home surgical simulators to enhance resident technical skill proficiency". The American Journal of Surgery 201.3 (2011): 15-319.

12. Ravia Bokhari MD., et al. "Design, Development and Validation of a Take-Home Simulator for Fundamental Laparoscopic Skills: Using Nintendo Wii ${ }^{\circledR}$ for Surgical Training”. American Surgery 76.6 (2010): 583-586.

\section{Volume 2 Issue 6 August 2019}

(C) All rights are reserved by José Luis Mosso Vázquez., et al. 